\title{
Comparative DNA methylation among females with neurodevelopmental disorders and seizures identifies TAC1 as a MeCP2 target gene
}

Kimberly A Aldinger ${ }^{1 *}$, Jasmine T Plummer ${ }^{1}$ and Pat Levitt ${ }^{1,2}$

\begin{abstract}
Background: Several proteins involved in epigenetic regulation cause syndromic neurodevelopmental disorders when human genes are mutated. More general involvement of epigenetic mechanisms in neurodevelopmental phenotypes is unclear.

Methods: In an attempt to determine whether DNA methylation differentiates clinical subgroups, profiling was performed on bisulfite converted DNA from lymphoblastoid cell lines (LCLs) in discovery $(n=20)$ and replication ( $n=40$ ) cohorts of females with Rett syndrome (RTT; $n=18)$, autism (AUT; $n=17)$, seizure disorder (SEZ; $n=6)$, and controls $(C T L ; n=19)$ using Illumina HumanMethylation27 arrays. TAC1 CpGs were validated using a Sequenom EpiTYPER assay and expression was measured in LCLs and postmortem brain. Chromatin immunoprecipitation was performed in HEK cells. Cells were treated with valproic acid and MeCP2 binding was assessed.

Results: Two female-only cohorts were analyzed. DNA methylation profiling in a discovery cohort identified 40 CpGs that exhibited statistically significant differential methylation $(\geq 15 \%)$ between clinical groups $(P<0.01)$. Hierarchical clustering and principal components analysis suggested neurodevelopmental groups were distinct from CTL, but not from each other. In a larger and more heterogeneous replication cohort, these $40 \mathrm{CpG}$ sites suggested no clear difference between clinical groups. Pooled analysis of DNA methylation across all 60 samples suggested only four differentially methylated $\mathrm{CpG}$ sites $(P<0.0005)$, including TAC1. TAC1 promoter CpG hypermethylation was validated in AUT and SEZ $(P<0.005)$. Analyzed for the first time in postmortem brain, TAC1 expression was reduced in cingulate cortex in RT and AUT+SEZ $(P=0.003)$. However, no significant difference in TAC1 promoter CPG methylation was detected in RTT and AUT+SEZ brains. Additional molecular analyses revealed that MeCP2 binds directly to the TAC1 promoter and is sensitive to antiepileptic drug treatment.

Conclusion: These data suggest that DNA methylation is not widely altered in RTT, consistent with subtle changes in gene expression previously observed. However, TAC1 may be an important target for further functional analyses in RTT. Studies of larger sample cohorts using primary cells that also consider shared clinical features and drug treatments may be required to address apparent subtle disruptions of DNA methylation in neurodevelopmental disorders.
\end{abstract}

Keywords: DNA methylation, MeCP2, Epigenetics, Autism, Rett syndrome, Epilepsy

\footnotetext{
* Correspondence: aldinger@usc.edu

${ }^{1}$ Zilkha Neurogenetic Institute, Keck School of Medicine of USC, 1501 San

Pablo Street, Los Angeles, CA 90089, USA

Full list of author information is available at the end of the article
} 


\section{Background}

DNA methylation is an epigenetic modification essential for a range of cellular functions including local and global transcription, genomic integrity, $\mathrm{X}$ chromosome inactivation, and genomic imprinting [1]. Epigenetic mechanisms are critical for a variety of neurobiological and cognitive processes including neurogenesis, stem cell maintenance [2], synaptic plasticity [3], learning and memory [4], and social imprinting [5]. The importance of epigenetic processes in normal brain function and development is further illustrated by the presence of neurodevelopmental deficits in syndromic disorders caused by mutations in genes associated with these processes. Rett syndrome (RTT), caused by mutations in the gene encoding methyl $\mathrm{CpG}$ binding protein 2 (MECP2), which binds to methylated DNA, is one such example [6].

DNA methylation is a covalent modification of the cytosine nucleotide that occurs in vertebrates at $\mathrm{CpG}$ dinucleotides to silence gene transcription directly, by inhibiting transcription factor binding, and indirectly, by recruiting methyl-CpG-binding proteins that engage in chromatin remodeling activities [7]. CpG islands located proximal to gene promoters contain a high density of CpG sites, yet they are often hypomethylated [8]. Nonetheless, differential DNA methylation at CpG islands, first identified in cancer, has more recently been associated with various neurological and neuropsychiatric disorders $[1,9,10]$.

We investigated whether lymphoblastoid cell line (LCL) DNA methylation profiles could be used to differentiate related neurodevelopmental disorders into clinical categories and identify specific target genes that might be relevant to pathophysiology. We also examined whether differential DNA methylation identified at gene promoters in a transformed peripheral tissue among distinct clinical groups reflects changes in gene expression in postmortem brain tissue. Finally, because seizures often co-occur in the neurodevelopmental disorders examined here, we also investigated the effects of valproic acid (VPA), a potent antiepileptic drug (AED) and histone deacetylase inhibitor, on MeCP2 binding.

\section{Methods}

\section{Samples}

Genomic DNA from females with RTT or seizure disorder (SEZ) was obtained from the Coriell Cell Repository [11]. Genomic DNA from age-matched females with autism (AUT) or controls (CTLs) was selected from the NIMH Center for Collaborative Genetic Studies on Mental Disorders Autism Pedigrees v5.0 [12]. All 60 DNA samples (Additional file 1: Table S1) used for methylation assays originated from LCLs. Fresh-frozen postmortem brain samples were obtained through the Autism Speakssupported Autism Tissue Program at the Harvard Brain
Tissue Resource Center [13] or the Eunice Kennedy Shriver National Institute of Child Health and Human Development Brain and Tissue Bank at the University of Maryland School of Medicine [14]. Tissue samples of the striatum, cingulate and temporal cortices were obtained from five RTT females and five CTL females (Additional file 1: Table S3). Additional samples of cingulate and temporal cortices were obtained from five AUT females and three additional CTL females.

\section{Genome-wide promoter CpG DNA methylation profiling}

Genomic DNA was bisulfite modified using the EZ DNA Methylation Kit (Zymo Research, Orange, CA, USA) and hybridized to the Illumina (San Diego, CA, USA) Infinium HumanMethylation27 BeadChip by the USC Epigenome Center as described elsewhere [15,16]. To evaluate array fidelity, DNA aliquots for six samples per clinical group from the discovery cohort were included in the replication cohort. The $\beta$ values ( 0 to 1.0 , where 0 represents no methylation and 1 represents complete methylation) for each $\mathrm{CpG}$ site were calculated as the methylated signal intensity divided by the sum of the methylated and unmethylated signals. Loci that possibly contained SNPs and/or repetitive elements were removed, leaving 21,583 probes representing CpG sites in 12,936 genes for analysis. Two AUT samples were excluded due to sex discrepancy (Additional file 1: Figure S1). No additional major chromosomal abnormalities were apparent. Copy number variants were previously reported for 11 samples included in this study (Additional file 1: Table S4).

\section{TAC1 DNA methylation validation}

The validation experiment included 56 samples from the Illumina discovery and replication cohorts. Another LCL DNA aliquot was bisulfite modified using the EZ DNA Methylation Kit (Zymo Research) by the USC Epigenome Center, according to the manufacturer's protocol. Genomic DNA was isolated from gray matter dissected from the cingulate cortex using the Wizard Genomic DNA Purification Kit (Promega, Madison, WI, USA) and was bisulfite modified. Sequenom primers (Additional file 1: Table S5) were designed to target the region that overlapped with Illumina probe location using the EpiDesigner BETA software [17]. The Sequenom (San Diego, CA, USA) MALDI-TOF mass spectrometry EpiTYPER Assay was performed by the Vanderbilt University Center for Human Genetics Research DNA Resources Core according to the manufacturer's protocol.

\section{TAC1 mRNA expression}

Total RNA was isolated from LCLs using the Illustra TriplePrep Kit (GE Healthcare Bio-Sciences Corp., Piscataway, NJ, USA) according to the manufacturer's protocol. Total RNA was isolated from gray matter-dissected 
brain tissue or HEK cell pellets using the RNeasy Plus Mini Kit (Qiagen, Valencia, CA, USA) according to the manufacturer's protocol. RNA quality was determined using an Agilent (Palo Alto, CA, USA) Bioanalyzer 2100 system; the RNA integrity number was $>8$ for all samples. cDNA was synthesized using the SuperScript III First Strand cDNA Synthesis Kit (Invitrogen, Carlsbad, CA, USA) according to the manufacturer's protocol using oligo dT primers. Quantitative RT-PCR was performed in triplicate for each sample using the Power SYBR Green PCR master mix (Life Technologies Corp., Carlsbad, CA, USA) and targetspecific primers (Additional file 1: Table S4) according to the manufacturer's recommendations. Assays were analyzed using a CFX96 Real-Time PCR detection system (Bio-Rad, Hercules, CA, USA). The delta cycle threshold $(\triangle \mathrm{Ct})$ of target relative to $A C T B$ was averaged per sample.

\section{MeCP2 chromatin immunoprecipitation}

The EZ-Magna ChIP A/G Chromatin Immunoprecipitation Kit (EMD Millipore Corporation, Billerica, MA, USA) was used with slight modifications to the manufacturer's protocol, as described in Additional file 1.

\section{Valproic acid treatment}

HEK cells and CTL LCLs were grown using standard conditions. After 24 hours, media was replaced with media containing $3 \mathrm{mM}$ VPA (Sigma-Aldrich Corp., St. Louis, MO, USA) and cells were grown for an additional 24 hours. Cells were processed for chromatin immunoprecipitation, as described above, or genomic DNA was extracted using a standard phenol:chloroform protocol and bisulfite modified for the TAC1 Sequenom EpiTYPER Assay, as described above.

\section{Statistical analysis}

lllumina probes with mean $|\Delta \beta| \geq 0.15$ between pairs of clinical groups within the discovery cohort were first selected for analysis $(n=391)$. Analysis of variance (ANOVA) and the false discovery rate (FDR) were performed to test the association between clinical group and DNA methylation for the selected probes. Illumina probes with $P<0.01$ and FDR $<0.10$ in the discovery cohort were evaluated in the replication cohort and in a pooled analysis that included all samples. Hierarchical clustering analysis (Ward's method) using dissimilarity matrices (1 - Pearson's correlation) and principal component analysis were performed to identify subjects with similar DNA methylation patterns. Statistical analyses were performed using $\mathrm{R}$ software [18].

Tukey post-hoc analysis was performed to identify pair-wise associations between clinical groups and DNA methylation for the probe that was significantly differentially methylated among clinical groups (cg14224417; TAC1). ANOVA and Tukey post-hoc tests were performed for each TAC1 promoter CpG site measured by the Sequenom assay. $t$ tests were used to assess the significance of TAC1 expression $(\Delta \mathrm{Ct})$ stratified by clinical group for each brain region and to assess the treatment effect in cell lines. To investigate the association between DNA methylation and mRNA expression in the cingulate cortex, stratified by clinical group, we fitted linear regression models. Statistical analyses were performed using SPSS version 18.0.3 software (IBM, Somers, NY, USA).

\section{Results}

Genome-wide CpG DNA methylation analysis: discovery cohort

Genome-wide DNA methylation profiling using LCLs from females diagnosed with a neurodevelopmental disorder and age-matched controls was performed in two independent subject cohorts: a discovery cohort $(n=20)$ and a replication cohort $(n=40)$. The discovery cohort contained LCL samples from females diagnosed with RTT $(n=10)$, AUT $(n=4)$, or CTL $(n=6)$ (Additional file 1 : Table S1). In discovery cohort samples, most probes had low DNA methylation levels (median $=0.04$ to 0.06 ; mean $=0.21$ to 0.24 ; range $=0.01$ to 0.99 ). Correlations among discovery cohort samples were similar across probes (Pearson's $r>0.98$ ), consistent with previous reports [19-24].

To identify robust DNA methylation differences $(\Delta \beta)$, we further analyzed all probes with pair-wise mean $|\Delta \beta| \geq 0.15$ among clinical groups within the discovery cohort. This threshold generated a normally distributed dataset containing 391 probes (Additional file 1: Table S2). Among these probes, 127 were differentially methylated between RTT and CTL, 104 between RTT and AUT, and 261 between AUT and CTL (Figure 1A). No probes were differentially methylated among all three pair-wise comparisons, but 53 probes were differentially methylated in either RTT or AUT compared with CTL. Interestingly, 42 probes that were differentially methylated between RTT and AUT and between AUT and CTL were opposite in magnitude. Twenty-six probes hypermethylated in RTT compared with AUT were hypomethylated in AUT compared with CTL, and 16 probes hypomethylated in RTT versus AUT were hypermethylated in AUT versus CTL. The distribution of hypermethylation and hypomethylation loci among comparison pairs was highly significant $\left(\chi^{2}(2-\mathrm{df})=14.17, P=0.0008\right)$. RTT was hypermethylated compared with CTL and AUT at 102 (80\%) and $74(72 \%)$ loci, respectively. AUT was also hypermethylated compared with CTL (62\%). The distribution of nonoverlapping loci hypermethylated (72\%) or hypomethylated (54\%) in AUT compared with CTL was significantly different than loci hypermethylated (82\%) or hypomethylated (18\%) between RTT and CTL $\left(\chi^{2}(1-\mathrm{df})=13.96, P=0.0002\right)$. 


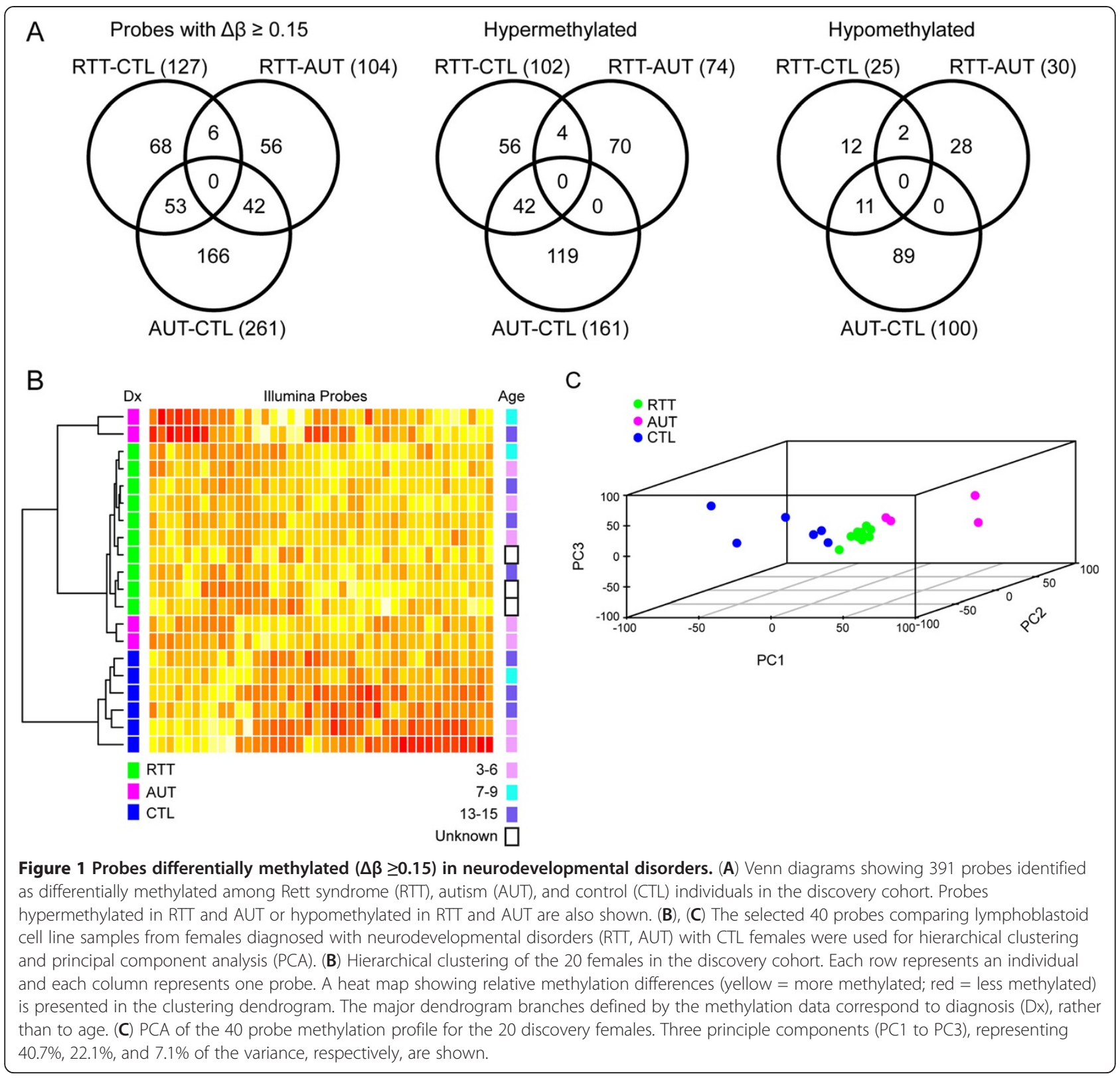

We performed ANOVA for 391 differentially methylated probes identified in the discovery cohort (Additional file 1: Table S2). Hierarchical clustering using the top 40 significant probes $(P<0.01$, FDR $<0.10)$ suggested discovery samples could be classified based on their DNA methylation profiles (Figure 1B). Principal component analysis further suggested three distinct clusters using the same 40 probes (Figure 1C). DNA methylation among the 40 probes suggested more homogeneity in RTT (mean Pearson's $r=0.93$ ) than among the samples in comparison groups (mean Pearson's $r=0.74$ and 0.83 for AUT and CTL groups, respectively).

\section{Genome-wide CpG DNA methylation: replication cohort}

Because seven of the 10 RTT females in this study were reported to have abnormal brain activity (seizures $(n=5)$ or subclinical abnormal EEG activity $(n=2)$ ], a common feature of RTT [25], we included an additional subject cohort in the replication experiment. We reasoned that this would address the possibility that AEDs, which can alter DNA methylation [26,27], might underlie some of the differential DNA methylation observed in the discovery cohort. The replication cohort contained LCL samples from females with RTT $(n=8)$, AUT $(n=13)$, SEZ $(n=6)$, or CTL $(n=13)$ (Additional file 1: Table S1). As measured 
in the discovery cohort, most probes had low DNA methylation levels in these samples (median $=0.06$ to 0.12 ; median $=0.21$ to 0.26 ; range $=0.01$ to 0.99 ). Correlations among samples were high (Pearson's $r>0.90$ ), but less similar than samples within the discovery cohort. To ensure technical fidelity across assay runs, replicates from the discovery cohort were included in the DNA methylation analysis of the replication cohort, with nearly perfect correlation between replicate pairs (Pearson's $r>0.99$ ) (Additional file 1: Figure S2). The 40 probes that distinguished clinical groups in the discovery cohort analysis similarly distinguished technical replicates, with high correlation between replicate pairs (Pearson's $r>0.98$ ) (Additional file 1: Figure S3). Duplicate samples were excluded from the replication cohort analysis.

In the replication cohort, hierarchical clustering using the 40 probes identified in the discovery cohort did not produce clustering of DNA methylation patterns by clinical group (Additional file 1: Figure S4A). Principal component analysis also failed to reveal distinct clinical clusters among the replication samples (Additional file 1: Figure S4B), suggesting greater molecular heterogeneity among the clinical samples included in the replication cohort.

\section{Locus-specific DNA methylation analysis}

To select particular loci with differential DNA methylation among clinical groups, we performed ANOVA for the 40 probes from the discovery cohort analysis using DNA methylation values from the replication cohort samples and in a pooled analysis (Table 1). We then selected probes below the conservative threshold of $P<0.001$ and FDR $<0.05$ from each analysis. In the discovery cohort, five loci showed significant differential DNA methylation (HOXA11, TCN1, PTCD2, TAC1, ETNK2). In the replication cohort, no locus was significant. In the pooled analysis, four loci were highly significant (PTCD2, TAC1, FLJ44881, SPAG7; P <0.0005, FDR <0.005). Overall, no locus emerged across these three analyses. However, TAC1 differential methylation approached significance in the replication analysis $(P=0.003$, FDR $=0.13)$, and was highly significant in both discovery and pooled analyses $(P<0.0005$, FDR $<0.05)$. TAC1 was previously implicated in RTT pathophysiology through convergent findings in RTT patients and mouse models [28-32]. We thus selected TAC1 to target for validation.

A Sequenom EpiTYPER assay was designed to quantify DNA methylation within the TAC1 promoter CpG island (Figure 2A). First, we determined whether DNA methylation levels detected at specific $\mathrm{CpG}$ sites within the Sequenom target region validated the Illumina assay results. Sequenom DNA methylation levels at two CpG sites located closest to the Illumina probe were highly correlated within samples (Additional file 1: Figure S5). Next, we evaluated whether significant differential methylation occurred among clinical groups using the Sequenom CpG methylation values. The clinical group had a significant main effect on DNA methylation at TAC1 CpG site 5 (ANOVA $\left.F_{(3,52)}=5.70, P=0.002\right)$. DNA methylation levels at this site had the strongest correlation with Illumina probe methylation values and validated the TAC1 results obtained from the genome-wide analysis.

To determine which clinical groups exhibited TAC1 differential methylation, we performed Tukey post-hoc pair-wise comparisons for discovery, replication, and pooled cohorts using Illumina and Sequenom data (Figure 2B). In the Illumina dataset, TAC1 was hypomethylated in RTT compared with AUT $(P=0.003)$ in the discovery cohort, and compared with SEZ $(P=0.008)$ in the pooled analysis. AUT was significantly hypermethylated relative to CTL in discovery $(P=0.0003)$ and pooled analyses $(P=0.004)$. SEZ was significantly hypermethylated versus CTL in replication $(P=0.001)$ and pooled analyses $(P=0.0001)$. Sequenom data confirmed significant AUT hypermethylation versus CTL in discovery $(P=0.02)$ and pooled analyses $(P=0.04)$, and SEZ hypermethylation versus CTL in replication $(P=0.01)$ and pooled analyses $(P=0.002)$. Overall, SEZ hypermethylation relative to CTL emerged with the most significant differential DNA methylation in both Illumina and Sequenom datasets.

\section{TAC1 expression in brain}

Since DNA methylation at CpG islands proximal to gene promoter regions is an important mediator of gene transcription [33], we evaluated whether TAC1 promoter DNA methylation differences were associated with differential expression. Because TAC1 is only weakly expressed in lymphocytes [34,35], evaluating expression differences in LCLs among clinical groups was uninformative (Additional file 1: Figure S6). However, if altered DNA methylation observed in LCLs occurred early in development, then differential DNA methylation detected in LCLs might exist in additional tissues. TAC1 is expressed in brain throughout development [36,37], and the brain is the primary tissue affected in neurodevelopmental disorders. We thus examined whether TAC1 DNA methylation status from a peripherally derived tissue correlates with central gene expression. DNA methylation analysis revealed significant TAC1 hypermethylation in SEZ versus CTL. Given that seizures commonly occur in RTT [25], we obtained postmortem brain samples from RTT females. TAC1 expression was assayed in three brain regions from age-matched RTT and CTL females (Additional file 1: Table S3) using quantitative RT-PCR (Figure 3A). TAC1 expression was significantly reduced in RTT cingulate cortex $(t(6)=2.98, P=0.03)$, with a trend for reduced expression in temporal cortex $(t(8)=2.22, P=0.06)$. No differences in TAC1 expression were detected in striatum $(t(7)=0.54, P=0.61)$. Given these results, we examined 
Table 1 Top 40 differentially methylated CpG sites identified in the discovery cohort

\begin{tabular}{|c|c|c|c|c|c|c|c|c|c|c|c|c|c|c|c|c|c|c|c|c|c|}
\hline \multirow[b]{2}{*}{ ILMN probe } & \multirow[b]{2}{*}{ Gene } & \multicolumn{2}{|l|}{ RTT } & \multicolumn{2}{|l|}{ AUT } & \multicolumn{2}{|l|}{ CTL } & \multicolumn{2}{|c|}{ Discovery $(n=20)$} & \multicolumn{2}{|l|}{ RTT } & \multicolumn{2}{|l|}{ AUT } & \multicolumn{2}{|l|}{ SEZ } & \multicolumn{2}{|l|}{ CTL } & \multicolumn{2}{|c|}{ Replication $(n=40)$} & \multicolumn{2}{|c|}{ Pooled $(n=60)$} \\
\hline & & Mean $\beta$ & SD & Mean $\beta$ & SD & Mean $\beta$ & SD & $P$ value & FDR & Mean $\beta$ & SD & Mean $\beta$ & SD & Mean $\beta$ & SD & Mean $\beta$ & SD & $P$ value & FDR & $P$ value & FDR \\
\hline cg17950095 & HOXA11 & 0.25 & 0.06 & 0.20 & 0.02 & 0.37 & 0.07 & 0.0002 & 0.03 & 0.23 & 0.12 & 0.27 & 0.11 & 0.27 & 0.09 & 0.25 & 0.12 & 0.86 & 0.92 & 0.42 & 0.46 \\
\hline cg00187686 & TCN1 & 0.38 & 0.07 & 0.41 & 0.13 & 0.18 & 0.07 & 0.0002 & 0.03 & 0.48 & 0.14 & 0.40 & 0.09 & 0.43 & 0.05 & 0.37 & 0.06 & 0.05 & 0.32 & 0.003 & 0.02 \\
\hline cg04527989 & PTCD2 & 0.83 & 0.04 & 0.64 & 0.11 & 0.83 & 0.06 & 0.0003 & 0.03 & 0.73 & 0.09 & 0.70 & 0.07 & 0.64 & 0.16 & 0.77 & 0.05 & 0.03 & 0.32 & 0.0001 & 0.001 \\
\hline cg14221171 & TAC1 & 0.17 & 0.09 & 0.35 & 0.08 & 0.10 & 0.06 & 0.0004 & 0.03 & 0.23 & 0.11 & 0.22 & 0.08 & 0.35 & 0.11 & 0.16 & 0.08 & 0.003 & 0.13 & 0.0001 & 0.001 \\
\hline cg03718539 & ETNK2 & 0.07 & 0.03 & 0.24 & 0.05 & 0.14 & 0.10 & 0.0004 & 0.03 & 0.11 & 0.03 & 0.12 & 0.06 & 0.16 & 0.06 & 0.09 & 0.04 & 0.07 & 0.32 & 0.02 & 0.05 \\
\hline cg09242541 & APITD1 & 0.53 & 0.14 & 0.45 & 0.11 & 0.24 & 0.07 & 0.001 & 0.04 & 0.41 & 0.22 & 0.43 & 0.16 & 0.32 & 0.08 & 0.54 & 0.13 & 0.04 & 0.32 & 0.28 & 0.34 \\
\hline cg18432105 & MYH2 & 0.74 & 0.06 & 0.62 & 0.03 & 0.57 & 0.11 & 0.001 & 0.06 & 0.66 & 0.09 & 0.70 & 0.07 & 0.71 & 0.03 & 0.67 & 0.13 & 0.62 & 0.81 & 0.17 & 0.24 \\
\hline cg14986136 & WBP5 & 0.13 & 0.08 & 0.13 & 0.07 & 0.32 & 0.10 & 0.001 & 0.06 & 0.21 & 0.14 & 0.17 & 0.08 & 0.20 & 0.05 & 0.19 & 0.11 & 0.77 & 0.90 & 0.17 & 0.24 \\
\hline cg18838701 & TNNI3 & 0.14 & 0.07 & 0.34 & 0.20 & 0.08 & 0.05 & 0.002 & 0.06 & 0.26 & 0.14 & 0.24 & 0.14 & 0.23 & 0.10 & 0.21 & 0.12 & 0.87 & 0.92 & 0.15 & 0.22 \\
\hline cg06537230 & DLX5 & 0.29 & 0.09 & 0.35 & 0.05 & 0.16 & 0.06 & 0.002 & 0.06 & 0.27 & 0.09 & 0.30 & 0.08 & 0.37 & 0.09 & 0.29 & 0.09 & 0.20 & 0.65 & 0.02 & 0.05 \\
\hline cg19002579 & SMPX & 0.64 & 0.09 & 0.69 & 0.04 & 0.42 & 0.17 & 0.002 & 0.06 & 0.64 & 0.12 & 0.61 & 0.08 & 0.66 & 0.08 & 0.60 & 0.09 & 0.54 & 0.78 & 0.02 & 0.05 \\
\hline cg06618866 & TLR2 & 0.16 & 0.05 & 0.26 & 0.09 & 0.10 & 0.05 & 0.002 & 0.06 & 0.16 & 0.08 & 0.18 & 0.09 & 0.16 & 0.05 & 0.14 & 0.05 & 0.53 & 0.78 & 0.02 & 0.05 \\
\hline cg23196831 & COL14A1 & 0.22 & 0.05 & 0.25 & 0.12 & 0.09 & 0.06 & 0.002 & 0.06 & 0.18 & 0.11 & 0.25 & 0.10 & 0.23 & 0.11 & 0.18 & 0.09 & 0.26 & 0.67 & 0.02 & 0.05 \\
\hline cg01541443 & C7orf41 & 0.78 & 0.07 & 0.61 & 0.10 & 0.79 & 0.05 & 0.002 & 0.06 & 0.67 & 0.10 & 0.67 & 0.08 & 0.68 & 0.03 & 0.66 & 0.17 & 0.99 & 0.99 & 0.33 & 0.38 \\
\hline cg19642007 & TNNT3 & 0.62 & 0.06 & 0.45 & 0.11 & 0.47 & 0.09 & 0.003 & 0.06 & 0.49 & 0.12 & 0.49 & 0.07 & 0.53 & 0.09 & 0.47 & 0.07 & 0.57 & 0.79 & 0.02 & 0.05 \\
\hline cg00176210 & ANK1 & 0.37 & 0.09 & 0.42 & 0.05 & 0.22 & 0.10 & 0.003 & 0.06 & 0.40 & 0.11 & 0.34 & 0.12 & 0.41 & 0.06 & 0.34 & 0.10 & 0.39 & 0.68 & 0.05 & 0.09 \\
\hline cg02049180 & INSRR & 0.65 & 0.07 & 0.43 & 0.19 & 0.64 & 0.03 & 0.003 & 0.06 & 0.62 & 0.11 & 0.62 & 0.07 & 0.64 & 0.04 & 0.61 & 0.09 & 0.92 & 0.95 & 0.23 & 0.31 \\
\hline cg09868035 & C20orf135 & 0.45 & 0.07 & 0.38 & 0.11 & 0.29 & 0.07 & 0.003 & 0.07 & 0.45 & 0.10 & 0.44 & 0.13 & 0.41 & 0.07 & 0.38 & 0.12 & 0.49 & 0.78 & 0.04 & 0.09 \\
\hline cg26227465 & IFNG & 0.69 & 0.07 & 0.74 & 0.09 & 0.49 & 0.17 & 0.003 & 0.07 & 0.58 & 0.15 & 0.60 & 0.13 & 0.60 & 0.14 & 0.55 & 0.19 & 0.79 & 0.90 & 0.08 & 0.13 \\
\hline cg20322862 & TGIF1 & 0.51 & 0.07 & 0.37 & 0.07 & 0.56 & 0.08 & 0.003 & 0.07 & 0.46 & 0.11 & 0.51 & 0.08 & 0.53 & 0.05 & 0.45 & 0.13 & 0.30 & 0.68 & 0.79 & 0.81 \\
\hline cg09404633 & $\angle M O D 1$ & 0.35 & 0.08 & 0.39 & 0.11 & 0.16 & 0.14 & 0.004 & 0.07 & 0.30 & 0.12 & 0.28 & 0.11 & 0.37 & 0.08 & 0.25 & 0.10 & 0.13 & 0.48 & 0.01 & 0.03 \\
\hline cg04555771 & CACNA2D2 & 0.33 & 0.10 & 0.44 & 0.10 & 0.16 & 0.14 & 0.004 & 0.07 & 0.28 & 0.08 & 0.32 & 0.11 & 0.37 & 0.06 & 0.36 & 0.15 & 0.39 & 0.68 & 0.40 & 0.45 \\
\hline cg10467098 & C11orf68 & 0.47 & 0.08 & 0.33 & 0.09 & 0.53 & 0.08 & 0.005 & 0.08 & 0.40 & 0.11 & 0.48 & 0.09 & 0.44 & 0.09 & 0.49 & 0.14 & 0.22 & 0.67 & 0.21 & 0.29 \\
\hline cg04091078 & SLCOICI & 0.73 & 0.04 & 0.58 & 0.14 & 0.71 & 0.04 & 0.005 & 0.09 & 0.68 & 0.07 & 0.67 & 0.08 & 0.71 & 0.04 & 0.67 & 0.05 & 0.50 & 0.78 & 0.05 & 0.09 \\
\hline cg05570980 & C3orf52 & 0.19 & 0.05 & 0.31 & 0.13 & 0.14 & 0.05 & 0.006 & 0.09 & 0.16 & 0.03 & 0.17 & 0.06 & 0.18 & 0.06 & 0.22 & 0.10 & 0.24 & 0.67 & 0.71 & 0.75 \\
\hline cg02441647 & COL8A1 & 0.08 & 0.03 & 0.13 & 0.04 & 0.25 & 0.15 & 0.006 & 0.09 & 0.17 & 0.09 & 0.14 & 0.06 & 0.17 & 0.07 & 0.15 & 0.12 & 0.86 & 0.92 & 0.25 & 0.32 \\
\hline cg18801691 & $D C C$ & 0.12 & 0.05 & 0.07 & 0.03 & 0.24 & 0.13 & 0.007 & 0.09 & 0.26 & 0.11 & 0.18 & 0.05 & 0.23 & 0.05 & 0.17 & 0.06 & 0.03 & 0.32 & 0.28 & 0.34 \\
\hline cg21306775 & FLJ44881 & 0.71 & 0.05 & 0.57 & 0.17 & 0.50 & 0.16 & 0.007 & 0.09 & 0.65 & 0.12 & 0.60 & 0.10 & 0.54 & 0.05 & 0.53 & 0.10 & 0.07 & 0.32 & 0.0002 & 0.002 \\
\hline cg14141399 & HAS1 & 0.89 & 0.03 & 0.79 & 0.16 & 0.69 & 0.16 & 0.007 & 0.09 & 0.76 & 0.15 & 0.81 & 0.05 & 0.76 & 0.09 & 0.75 & 0.12 & 0.52 & 0.78 & 0.05 & 0.09 \\
\hline cg12815142 & SPAG7 & 0.69 & 0.05 & 0.56 & 0.06 & 0.53 & 0.15 & 0.007 & 0.09 & 0.58 & 0.09 & 0.53 & 0.08 & 0.60 & 0.04 & 0.51 & 0.10 & 0.07 & 0.32 & 0.0003 & 0.003 \\
\hline cg14062083 & KRTAP13-4 & 0.56 & 0.08 & 0.42 & 0.13 & 0.39 & 0.10 & 0.007 & 0.09 & 0.46 & 0.10 & 0.45 & 0.09 & 0.57 & 0.04 & 0.44 & 0.12 & 0.05 & 0.32 & 0.003 & 0.02 \\
\hline cg20311730 & NLRP10 & 0.64 & 0.04 & 0.60 & 0.11 & 0.47 & 0.14 & 0.007 & 0.09 & 0.59 & 0.10 & 0.58 & 0.05 & 0.60 & 0.05 & 0.54 & 0.08 & 0.34 & 0.68 & 0.004 & 0.02 \\
\hline
\end{tabular}


Table 1 Top 40 differentially methylated CpG sites identified in the discovery cohort (Continued)

\begin{tabular}{|c|c|c|c|c|c|c|c|c|c|c|c|c|c|c|c|c|c|c|c|c|c|}
\hline cg00415993 & $F 2 R L 2$ & 0.67 & 0.10 & 0.65 & 0.11 & 0.44 & 0.18 & 0.008 & 0.09 & 0.58 & 0.08 & 0.51 & 0.13 & 0.59 & 0.07 & 0.44 & 0.19 & 0.10 & 0.42 & 0.002 & 0.01 \\
\hline cg00318573 & CHRNA4 & 0.32 & 0.12 & 0.18 & 0.09 & 0.14 & 0.07 & 0.008 & 0.09 & 0.20 & 0.08 & 0.19 & 0.11 & 0.25 & 0.12 & 0.16 & 0.09 & 0.32 & 0.68 & 0.01 & 0.03 \\
\hline cg15350036 & $C R O T$ & 0.82 & 0.04 & 0.75 & 0.07 & 0.66 & 0.13 & 0.008 & 0.09 & 0.78 & 0.04 & 0.72 & 0.09 & 0.73 & 0.08 & 0.67 & 0.20 & 0.35 & 0.68 & 0.01 & 0.04 \\
\hline cg04993257 & PLAC2 & 0.44 & 0.07 & 0.35 & 0.08 & 0.26 & 0.15 & 0.009 & 0.09 & 0.39 & 0.07 & 0.41 & 0.10 & 0.44 & 0.07 & 0.47 & 0.10 & 0.27 & 0.67 & 0.82 & 0.82 \\
\hline cg03273615 & RBM41 & 0.40 & 0.08 & 0.33 & 0.12 & 0.22 & 0.11 & 0.009 & 0.09 & 0.35 & 0.12 & 0.35 & 0.10 & 0.38 & 0.04 & 0.32 & 0.13 & 0.73 & 0.88 & 0.08 & 0.13 \\
\hline cg11505048 & APOBEC4 & 0.83 & 0.06 & 0.72 & 0.14 & 0.88 & 0.03 & 0.009 & 0.09 & 0.71 & 0.09 & 0.69 & 0.07 & 0.69 & 0.07 & 0.73 & 0.08 & 0.60 & 0.80 & 0.01 & 0.04 \\
\hline cg01145396 & CHRNG & 0.58 & 0.07 & 0.57 & 0.08 & 0.43 & 0.12 & 0.009 & 0.09 & 0.49 & 0.07 & 0.49 & 0.08 & 0.57 & 0.06 & 0.52 & 0.14 & 0.36 & 0.68 & 0.32 & 0.37 \\
\hline cg13370916 & STARD8 & 0.58 & 0.06 & 0.51 & 0.02 & 0.40 & 0.16 & 0.009 & 0.09 & 0.48 & 0.10 & 0.50 & 0.09 & 0.51 & 0.05 & 0.47 & 0.10 & 0.70 & 0.87 & 0.04 & 0.09 \\
\hline
\end{tabular}

Probes with $P<0.001$ and FDR $<0.05$ are in bold. Probes with $\mathrm{P}<0.01$ and FDR $<0.05$ are in italic. AUT autism, CTL control, FDR false discovery rate, LLMN Probe Illumina HumanMethyl27 probe name; $P$ value analysis of variance $P$ value, $R T T$ Rett syndrome, $S D$ standard deviation. 


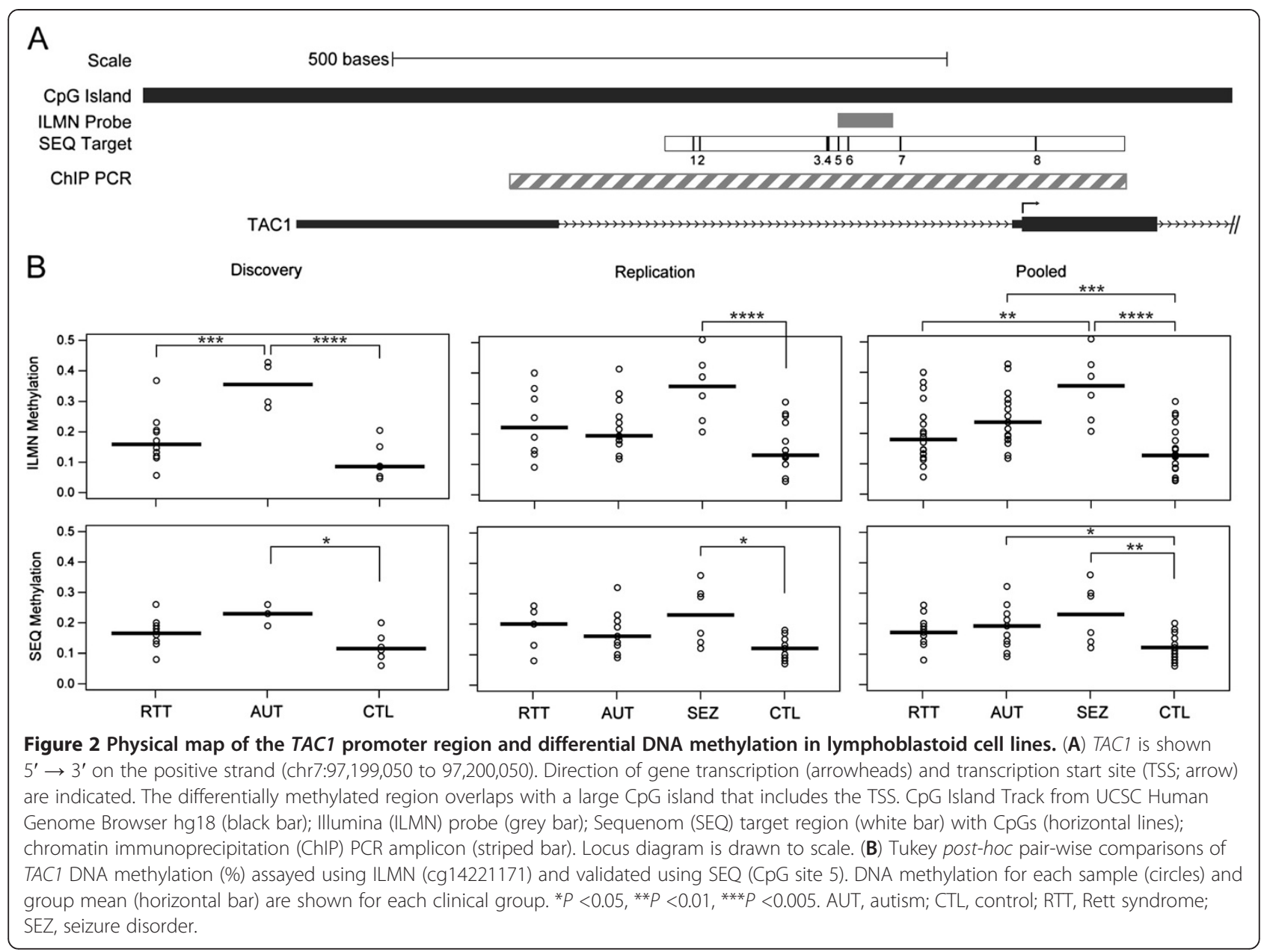

TAC1 expression in additional postmortem brain samples obtained from female subjects diagnosed with AUT and for which the patient's cause of death was ascribed to SEZ [38] (Figure 3B). Indeed, TAC1 expression was also reduced in $\mathrm{AUT}+\mathrm{SEZ}$ cingulate cortex, approaching significance $(t(5)=2.29, P=0.07)$. No significant difference in TAC1 expression was detected in AUT temporal cortex $(t(7)=0.98, P=0.36)$. A combined analysis using all brain samples and comparing TAC1 expression in the cingulate cortex suggested a significant TAC1 reduction in affected brains $(t(12)=3.67, P=0.003)$ (Figure $3 C$ ).

\section{TAC1 DNA methylation in brain}

Several studies have reported differential DNA methylation among brain regions in postmortem tissue $[39,40]$. To determine whether DNA methylation at the TAC1 promoter varied among brain regions, we selected Illumina DNA methylation data (cg14224417) assayed in four brain regions from female samples in a previous study [39]. The TAC1 promoter displayed significant differential DNA methylation among certain brain regions in females (Additional file 1: Figure S7).
To determine whether the reduced TAC1 expression observed in cingulate cortex of seizure phenotype (RTT and AUT+SEZ) brains may be associated with differential DNA methylation, we extracted DNA from the same brain samples used for the expression studies and evaluated TAC1 DNA methylation using the Sequenom EpiTYPER assay. As expected, an inverse correlation between TAC1 promoter DNA methylation and expression was observed for both seizure phenotype and CTL cingulate cortex samples (Figure 3D). However, no significant differential DNA methylation was detected at TAC1 CpG site 5 between seizure phenotype and CTL cingulate cortex samples $(t(16)=-0.71$, $P=0.49)$, nor for any of the other CpG sites in the TAC1 promoter locus (data not shown). DNA methylation at TAC1 CpG site 5 was also not a significant predictor of TAC1 expression in the cingulate cortex of CTL brains $(\beta=-6.09, P=0.78)$. However, in this small sample, there was a trend suggesting DNA methylation at TAC1 CpG site 5 may predict TAC1 expression in the cingulate cortex of seizure phenotype brains $(\beta=-6.40, P=0.09)$. 


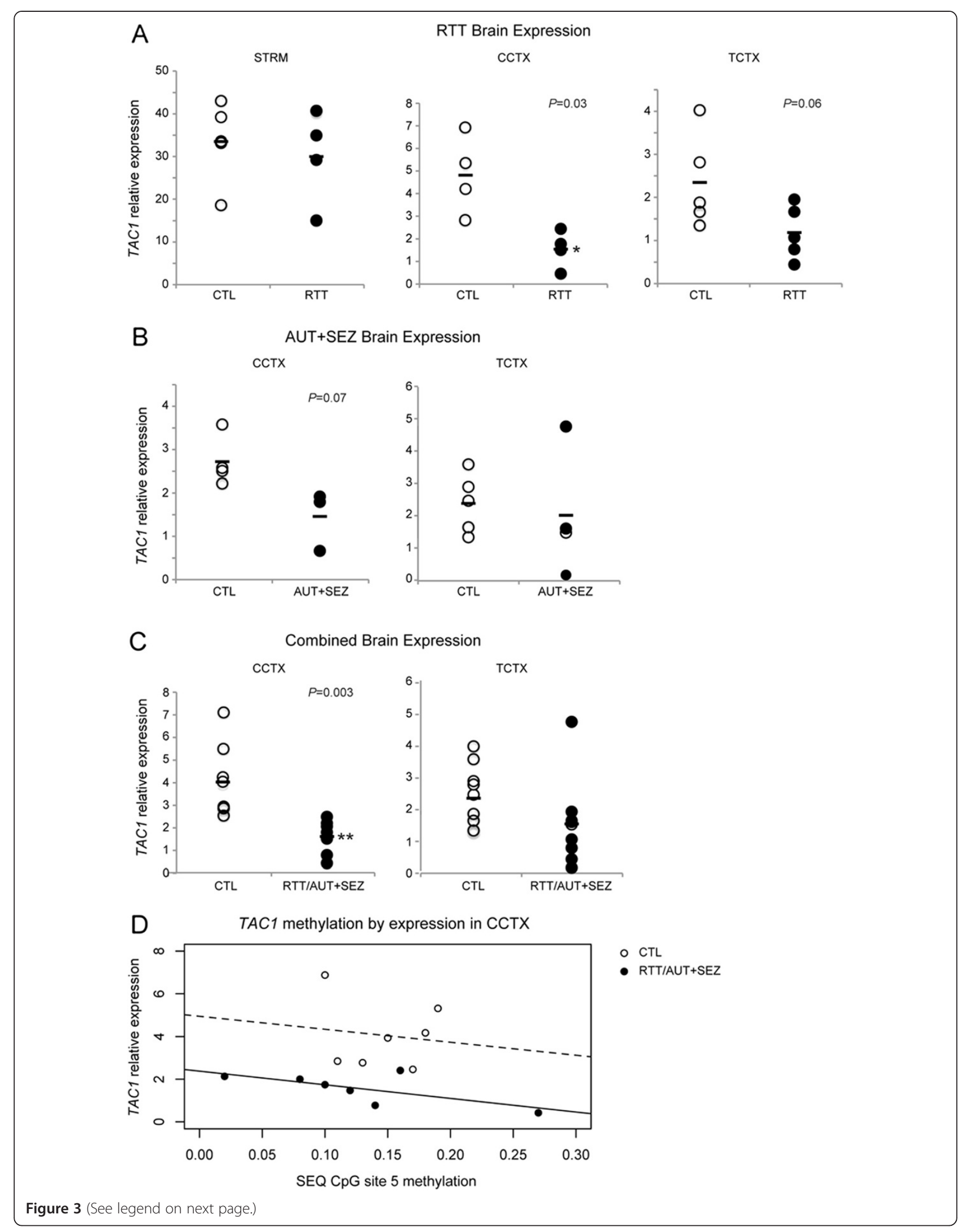


(See figure on previous page.)

Figure 3 TAC1 expression and DNA methylation in the brain. (A), (B), (C) TAC1 mRNA assayed by quantitative RT-PCR in the striatum (STR), cingulate (CCTX) and temporal cortex (TCTX) of female brains. Data are presented as relative expression of TAC1 compared with ACTB for each sample (circles) and group mean (horizontal bar). ${ }^{*} P<0.05$; ${ }^{*} P<0.01$. (D) Scatter plot of DNA methylation at Sequenom (SEQ) CPG site 5 and TAC1 expression in the CCTX stratified by seizure phenotype (RTT/AUT+SEZ) or control (CTL). Regression lines for seizure phenotype (black) and CTL (dashed) indicate an inverse relationship between DNA methylation and expression in CCTX. AUT, autism; RTT, Rett syndrome; SEZ, seizure disorder.

\section{MeCP2 binds to the TAC1 promoter}

RTT is mostly caused by MECP2 coding mutations [6]. More recently, increased $M E C P 2$ expression was detected in temporal cortex of patients with intractable temporal lobe epilepsy [41]. To determine whether TAC1 is a MeCP2 target in vivo, we performed chromatin immunoprecipitation assays in HEK cells, which express high levels of TAC1 [34,35]. Anti-MeCP2 specifically precipitates TAC1 DNA, while control IgG yields no enrichment of binding to the TAC1 sequence (Figure 4A), supporting direct binding of MeCP2 to the TAC1 promoter region (Figure 2A). We further examined the possibility that DNA hypermethylation detected at the TAC1 promoter in seizure-associated phenotypes was due to AED treatment. VPA is an anticonvulsant, commonly administered for seizure control in RTT, and a potent histone deacetylase inhibitor that can directly alter DNA methylation in vitro [26]. Following VPA treatment of HEK cells, anti-MeCP2 failed to precipitate TAC1 DNA, whereas anti-acetylated histone 3 precipitates more DNA, as expected (Figure 4A, B).

\section{Discussion}

The present study demonstrates both the challenges and potential promise of utilizing genome-wide DNA methylation patterns in LCLs derived from peripheral cells to distinguish individuals with different neurodevelopmental disorders. An initial analysis of LCLs from CTLs and the neurodevelopmental disorders RTT and AUT was sufficiently specific to cluster each cohort. However, a larger replication sample did not repeat this finding. Importantly, the additional subject analyses revealed that secondary clinical complications that can accompany many neurodevelopmental disorders, such as SEZ, may have significant effects on DNA methylation status. In contrast to diseases like cancer [42], alterations in genomewide DNA methylation patterns in neurodevelopmental disorders are likely to be subtle. We therefore suggest that utilizing samples from patients with detailed clinical and molecular information on each subject included in such studies will be required to discover unique disorder-specific DNA methylation patterns that will be useful for sorting clinical heterogeneity within and across disorders.

Analysis across all clinical groups suggested differential methylation of the TAC1 gene in LCLs derived from peripheral cells. This turned out to be highly relevant with regard to RTT, given that it is one of the few genes whose expression is consistently reduced in the brains of Mecp2 mutant mice [31,32]. Our study is the first to examine TAC1 expression in postmortem brain samples from RTT subjects. We demonstrate reduced TAC1 expression in brain samples from subjects defined by clinical diagnosis and presence of seizures. The principle protein responsible for DNA methylation-dependent transcriptional regulation is $\mathrm{MeCP} 2$, encoded by a gene mutated in RTT. Further analysis showed direct MeCP2-TAC1 promoter binding, but also suggested that the interaction is highly sensitive to the AED VPA in vitro.

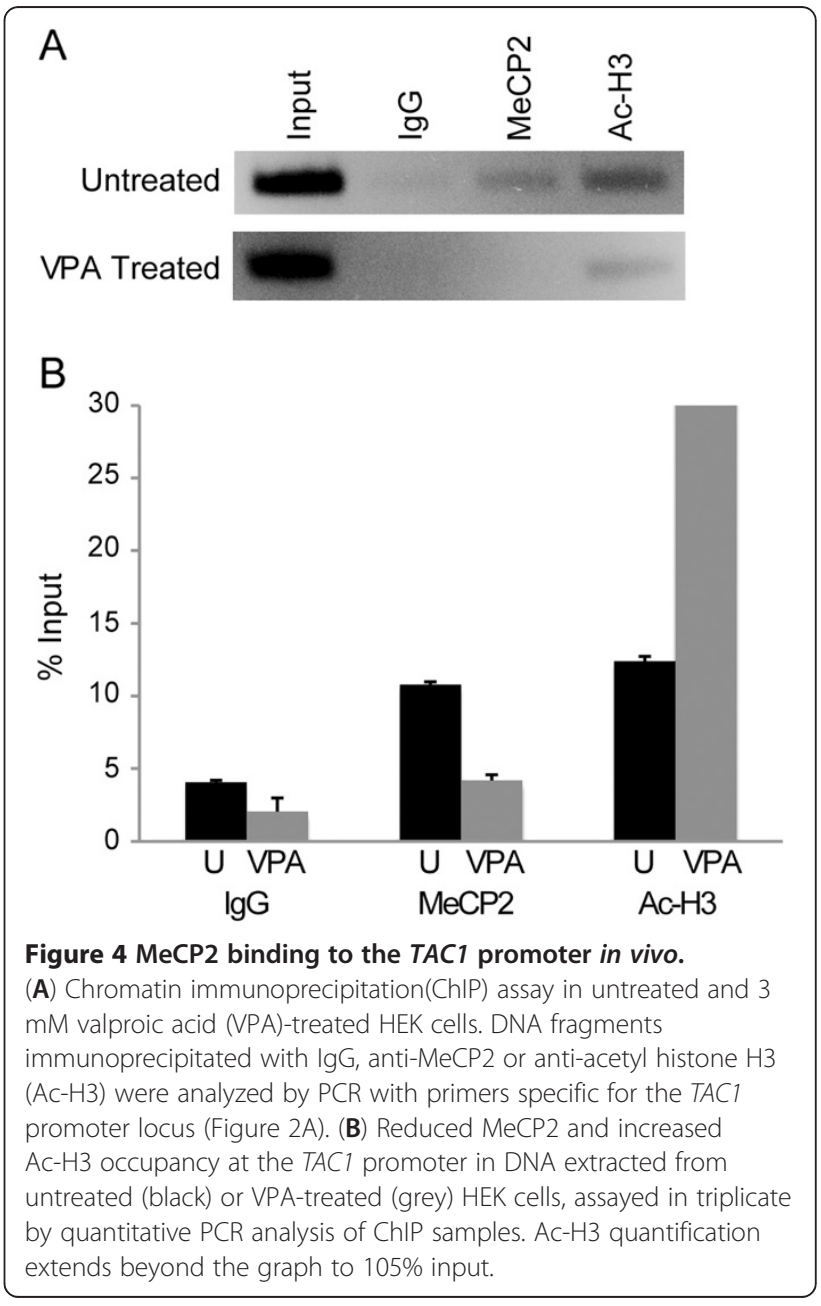


Collectively, these findings reflect the complexity of utilizing epigenetic differences in categorical analyses based on a clinical diagnosis. The challenges and utility of the approaches used here are discussed below.

\section{Challenges of clinical stratification using differential DNA methylation patterns}

DNA methylation is one of several key mechanisms through which gene expression is controlled. Analysis of DNA methylation patterns has been the focus of comparative studies in normal and malignant tissues [43], biopsied samples from peripheral organs [44-46], and in white blood cells from control and disorder-diagnosed populations $[21,47,48]$. This strategy is a challenge particularly with neurological disorders, because molecular assays of brain are often not possible in patients. Several studies have examined DNA methylation patterns in postmortem brain tissue from control subjects and those with a psychiatric disorder diagnosis [49,50], but the relationship between peripheral and central measures of DNA methylation are only beginning to emerge [45]. Moreover, there is variability in the fidelity of different assays used in studies, and few studies use secondary methods to validate alternations in specific DNA methylation sites. The $27 \mathrm{~K}$ chip has been shown to be highly reliable and sensitive across assay runs $[19,23]$, and we showed in the present study that replicate samples run at different times, independent of diagnostic group, are $>99 \%$ identical in terms of global DNA methylation patterns. One caveat of our study was the use of the $27 \mathrm{~K}$ chip, the only validated chip at the time we initiated the studies. This chip has high fidelity and samples CpG sites across the genome, although it only probes approximately one-half of the genes in the genome. Future studies using assays with greater coverage will therefore possibly reveal new patterns of DNA methylation not recognized here. An additional technical caveat is the use of patient LCLs. These cells provide an opportunity to assess patient-derived samples that are commonly accumulated in repositories in sufficient numbers for the study of rare neurological disorders. However, the transformation and growth processes of these cell lines may lead to epigenetic changes not present in the primary patient cells [51]. These challenges notwithstanding, the present study emphasizes the importance of controlling for complex clinical phenotypes, such as seizures. The data presented here suggest that the state-dependent status of DNA methylation patterns, as well as central and peripheral differences, may make it challenging to detect disorder-specific patterns that consistently reflect categorical differences across samples.

\section{DNA methylation in Rett syndrome}

We initially focused on RTT due to the importance of $\mathrm{MeCP} 2$ in regulating transcription through binding to methylated DNA. The possibility of altered DNA methylation in RTT had not previously been investigated in clinical samples. We hypothesized that the altered MeCP2 function in RTT might lead to compensatory changes in the DNA methylation status of certain genes. In fact, the initial sample illustrated that using LCLs from patients, analyzed using cluster and principle component methods of the top differentially methylated genes, distinguished the clinical groups from CTL. More than double the number of CpG sites showed differential DNA methylation between AUT and CTL $(n=261)$ than between RTT and CTL $(n=127)$. At first glance, these results were surprising given our hypothesis that RTT would display the greatest differential DNA methylation from CTL because of the involvement of MeCP2 in this disorder. However, the more limited differences in the first RTT cohort are not unprecedented. For example, in another neurodevelopmental disorder, Cornelia de Lange syndrome, fewer CpG sites demonstrated differential methylation than the number of genes with expression differences [52,53]. Expression profiling in AUT has been more compelling than in RTT. Hundreds of differentially expressed genes in LCLs and brain from AUT subjects have been reported [54,55], while global gene expression analyses have failed to reveal any dramatic differences in RTT compared with control subjects using a variety of tissues [56-61]. The present data showing an inverse correlation between DNA methylation and TAC1 expression, despite the reduced TAC1 expression in cortex, may be a reflection of the small sample size and/or the complex relationship between transcriptional regulation and gene expression.

The initial promise of categorizing clinical groups by DNA methylation pattern from the first cohort did not replicate in a second, larger sample that included LCLs from individuals with SEZ. DNA methylation status is highly influenced by nonheritable factors, including physiological state [62], medications [26] and even diet [63]. We reasoned that since the presence of seizures in neurodevelopmental disorders is common and a hallmark of RTT, it could serve as a unifying feature in the clinically diagnosed populations. In fact, using LCLs from subjects with SEZ and postmortem brain tissue from AUT cases in which seizures were noted in the medical history, or was the cause of death, we show that DNA methylation patterns of specific genes may be more related to seizure status, a finding that has not been previously reported. The repositories that provided the LCLs and postmortem brain samples do not collect sufficient information regarding medication status. We can therefore only suggest that contributions to DNA methylation status at certain sites may be due in part to drug treatment effects. To investigate this possibility, VPA-treated HEK cells showed dramatic changes in 
DNA methylation of the TAC1 gene; additional sites were probably also impacted by VPA. Interestingly, VPA treatment altered MeCP2 binding to the TAC1 promoter, which suggests that this putative regulatory interaction may be responsible in part for the consistent reduction of TAC1 expression in cortical brain regions that we assayed, although not in striatum.

\section{TAC1 as a target gene in Rett syndrome}

The TAC1 DNA methylation and gene expression changes were not expected, although this gene has been a candidate target in RTT due to the finding of reduced expression in Mecp 2 mutant mice [31,32]. The present study is the first to identify molecular changes of TAC1 in brain samples from RTT patients. TAC1 gene expression changes were statistically significant in the cingulate cortex, with a trend that almost reached significance in the temporal cortex given the limited sample size; other brain regions should be evaluated in the future. It is noteworthy that TAC1 expression changes were not observed in the striatum, indicating that seizure pathophysiology and AEDs do not produce global, nonspecific effects throughout the brain. The alterations in the cingulate cortex are of functional interest, due to the role of this cortical region in executive function and complex multisensory processing [64-66], both of which are disrupted in AUT and SEZ $[67,68]$. The TAC1 gene encodes neurokinins and substance $\mathrm{P}$. These neuromodulators are expressed in nociceptive primary sensory neurons, and serve as modulators of pain perception and inflammation [69]. In the neocortex, substance $\mathrm{P}$ is an excitatory neuromodulator of projection neuron activity [70]. Furthermore, there are several convergent findings related to expression of this peptide and RTT. First, substance P is reduced in the cerebrospinal fluid of RTT patients [28]. Second, substance $\mathrm{P}$ immunoreactivity is reduced in brains of RTT patients compared with age-matched controls [30], although not in the bowels (enteric nervous system) [29]. Third, Tac1 expression is reduced in the hypothalamus of juvenile male Mecp2 mutant mice [31] and in adult male mice with postnatal Mecp2 loss [32]. Finally, respiratory abnormalities are a clinical hallmark of RTT [71] and neurons in the rhythm-generating center of the respiratory network are dynamically regulated by substance $P$ [72]. The discovery of TAC1 deficiency in RTT thus adds to other convergent lines of evidence implicating the neuropeptides in RTT pathophysiology. Further consideration of substance $\mathrm{P}$ and other neuropeptides transcribed from the TAC1 locus as therapeutic targets in RTT and AUT+SEZ is warranted.

\section{Conclusion}

We have examined genome-wide CpG DNA methylation patterns in LCLs from females with three related neurodevelopmental disorders. The initial analysis suggested promise of differential DNA methylation patterns among clinical disorders, but failure to replicate this finding in a second, larger cohort may reflect a more complex relationship between DNA methylation status and neurological disorder. This may be due to the presence of seizures in neurodevelopmental disorders and/or the use of medications that can affect DNA methylation, such as VPA. Currently, there is a limited understanding of the complex relationship between DNA methylation status of peripheral cells and brain tissues. Interestingly, we found that hypermethylation at the TAC1 promoter in LCLs was correlated with reduced expression in certain brain regions, despite the lack of a change in DNA methylation of the $T A C 1$ promoter in the brain. Further, we show that MeCP2 directly binds to the TAC1 promoter in vivo, and this binding can be altered dramatically by AED treatment. These findings suggest that future studies with larger sample cohorts should consider shared co-occurring clinical features, such as seizures, as well as specific drug treatments in order to more thoroughly address the role of altered DNA methylation in neurodevelopmental disorders.

\section{Availability of supporting data}

These data have been deposited into the NCBI Gene Expression Omnibus [73] and are accessible through GEO Series accession number GSE345099.

\section{Additional file}

Additional file 1: A pdf file containing supplementary methods, Figures S1 to S7 and Tables S1 to S5.

\section{Abbreviations}

AED: Antiepileptic drug; ANOVA: Analysis of variance; AUT: Autism; CTL: Control; FDR: False discovery rate; LCL: Lymphoblastoid cell line; PCR: Polymerase chain reaction; RT: Reverse transcriptase; RTT: Rett syndrome; SEZ: Seizure disorder; SNP: Single nucleotide polymorphism; VPA: Valproic acid.

\section{Competing interests}

The authors declare that they have no competing interests.

\section{Authors' contributions}

KAA and PL designed the study. KAA performed experiments and analyzed data. JTP performed experiments. KAA and PL drafted the manuscript. All authors read, edited and approved the final manuscript.

\section{Acknowledgements}

This work was supported by the Epilepsy Foundation of Greater Los Angeles and Award Number KL2RR031991 from the National Center for Research Resources. KAA was a KL2 Scholar awarded under the KL2 Mentoring Research Career Development Award through Southern California Clinical and Translational Science Institute at University of Southern California, Keck School of Medicine. The authors are grateful to Evan Cohen (USC), Paxton Baker (VCMU), Cara Sutcliffe (VCMU), and Daniel J Weisenberger (USC Epigenome Core) for technical assistance, and Christianne J Lane for statistical advice. 


\section{Author details}

'Zilkha Neurogenetic Institute, Keck School of Medicine of USC, 1501 San Pablo Street, Los Angeles, CA 90089, USA. ²Department of Cell \&

Neurobiology, Keck School of Medicine of USC, Los Angeles, CA 90089, USA.

Received: 15 March 2013 Accepted: 22 May 2013

Published: 11 June 2013

\section{References}

1. Robertson KD: DNA methylation and human disease. Nat Rev Genet 2005 6:597-610.

2. Ma DK, Marchetto MC, Guo JU, Ming GL, Gage FH, Song H: Epigenetic choreographers of neurogenesis in the adult mammalian brain. Nat Neurosci 2010, 13:1338-1344.

3. Feng J, Fan G: The role of DNA methylation in the central nervous system and neuropsychiatric disorders. Int Rev Neurobiol 2010, 89:67-84.

4. Day JJ, Sweatt JD: Epigenetic mechanisms in cognition. Neuron 2011, 70:813-829

5. Bagot RC, Meaney MJ: Epigenetics and the biological basis of gene $x$ environment interactions. J Am Acad Child Adolesc Psychiatry 2010, 49:752-771.

6. Amir RE, Van den Veyver IB, Wan M, Tran CQ, Francke U, Zoghbi HY: Rett syndrome is caused by mutations in X-linked MECP2, encoding methyl-CpG-binding protein 2. Nat Genet 1999, 23:185-188.

7. Nan X, Ng HH, Johnson CA, Laherty CD, Turner BM, Eisenman RN, Bird A: Transcriptional repression by the methyl-CpG-binding protein $\mathrm{MeCP} 2$ involves a histone deacetylase complex. Nature 1998, 393:386-389.

8. Miranda TB, Jones PA: DNA methylation: the nuts and bolts of repression. J Cell Physiol 2007, 213:384-390

9. Tsankova N, Renthal W, Kumar A, Nestler EJ: Epigenetic regulation in psychiatric disorders. Nat Rev Neurosci 2007, 8:355-367.

10. Jakovcevski M, Akbarian S: Epigenetic mechanisms in neurological disease. Nat Med 2012, 18:1194-1204

11. Coriell Cell Repository. http://ccr.coriell.org/.

12. NIMH Center for Collaborative Genetic Studies on Mental Disorders. https://www.nimhgenetics.org/.

13. Harvard Brain Tissue Resource Center. http://www.brainbank.mclean.org/

14. NICHD Brain and Tissue Bank. http://medschool.umaryland.edu/BTBank/.

15. Teschendorff AE, Menon U, Gentry-Maharaj A, Ramus SJ, Weisenberger DJ, Shen H, Campan M, Noushmehr H, Bell CG, Maxwell AP, Savage DA, Mueller-Holzner E, Marth C, Kocjan G, Gayther SA, Jones A, Beck S, Wagner W, Laird PW, Jacobs IJ, Widschwendter M: Age-dependent DNA methylation of genes that are suppressed in stem cells is a hallmark of cancer. Genome Res 2010, 20:440-446.

16. Noushmehr H, Weisenberger DJ, Diefes K, Phillips HS, Pujara K, Berman BP, Sulman EP, Bhat KP, Verhaak RG, Hoadley KA, Hayes DN, Perou CM, Schmidt HK, Ding L, Wilson RK, Van Den Berg D, Shen H, Bengtsson H, Neuvial P, Cope LM, Buckley J, Herman JG, Baylin SB, Laird PW, Aldape K: Cancer genome atlas research network: identification of a $\mathrm{CpG}$ island methylator phenotype that defines a distinct subgroup of glioma. Cancer Cell 2010, 17:510-522.

17. EpiDesigner BETA. http://www.epidesigner.com/

18. R software. http://r-project.org/.

19. Bibikova M, Le J, Barnes B, Saedinia-Melnyk S, Zhu L, Shen R, Gunderson KL: Genome-wide DNA methylation profiling using Infinium assay. Epigenomics 2009, 1:117-200.

20. Chowdhury S, Erickson SW, MacLeod SL, Cleves MA, Hu P, Karim MA, Hobbs CA: Maternal genome-wide DNA methylation patterns and congenital heart defects. PLOS One 2011, 6:e16506.

21. Dempster EL, Pidsley R, Schalkwyk LC, Owens S, Georgiades A, Kane F, Kalidini S, Picchioni M, Kravariti E, Toulopoulou T, Murray RM, Mill J: Disease-associated epigenetic changes in monozygotic twins discordant for schizophrenia and bipolar disorder. Hum Mol Genet 2011, 20:4786-4796.

22. Grigoriu A, Ferreira JC, Choufani S, Baczyk D, Kingdom J, Weksberg R: Cell specific patterns of methylation in the human placenta. Epigenetics 2011, 6:368-379.

23. Weisenberger DJ, Van Den Berg D, Pan F, Berman BP, Laird PW: Comprehensive DNA Methylation Analysis on the Illumina Infinium Assay Platform. San Diego, CA: Illumina; 2008.
24. Naumova OY, Lee M, Koposov R, Szyf M, Dozier M, Grigorenko EL: Differential patterns of whole-genome DNA methylation in institutionalized children and children raised by their biological parents. Dev Psychopathol 2012, 24:143-155.

25. Glaze DG, Percy AK, Skinner S, Motil KJ, Neul JL, Barrish JO, Lane JB, Geerts SP, Annese F, Graham J, McNair L, Lee HS: Epilepsy and the natural history of Rett syndrome. Neurology 2010, 74:909-912.

26. Detich N, Bovenzi V, Szyf M: Valproate induces replication-independent active DNA demethylation. J Biol Chem 2003, 278:27586-27592.

27. Dong E, Chen Y, Gavin DP, Grayson DR, Guidotti A: Valproate induces DNA demethylation in nuclear extracts from adult mouse brain. Epigenetics 2010, 5:730-735.

28. Matsuishi T, Nagamitsu S, Yamashita Y, Murakami Y, Kimura A, Sakai T, Shoji $\mathrm{H}$, Kato H, Percy AK: Decreased cerebrospinal fluid levels of substance P in patients with Rett syndrome. Ann Neurol 1997, 42:978-981.

29. Deguchi K, Reyes C, Chakraborty S, Antalffy B, Glaze D, Armstrong D: Substance $P$ immunoreactivity in the enteric nervous system in Rett syndrome. Brain Dev 2001, 23(Suppl 1):S127-S132.

30. Deguchi K, Antalffy BA, Twohill LJ, Chakraborty S, Glaze DG, Armstrong DD Substance P immunoreactivity in Rett syndrome. Pediatr Neurol 2000, 22:259-266.

31. Chahrour M, Jung SY, Shaw C, Zhou X, Wong ST, Qin J, Zoghbi HY: MeCP2, a key contributor to neurological disease, activates and represses transcription. Science 2008, 320:1224-1229.

32. McGraw CM, Samaco RC, Zoghbi HY: Adult neural function requires MeCP2. Science 2011, 333:186.

33. Deaton $A M, B i r d A: C p G$ islands and the regulation of transcription. Genes Dev 2011, 25:1010-1022.

34. Wu C, Orozco C, Boyer J, Leglise M, Goodale J, Batalov S, Hodge CL, Haase J, Janes J, Huss JW 3rd, Su AL: BioGPS: an extensible and customizable portal for querying and organizing gene annotation resources. Genome Biol 2009, 10:R130.

35. BioGPS. http://biogps.org/.

36. Johnson MB, Kawasawa YI, Mason CE, Krsnik Z, Coppola G, Bogdanovic D, Geschwind DH, Mane SM, State MW, Sestan N: Functional and evolutionary insights into human brain development through global transcriptome analysis. Neuron 2009, 62:494-509.

37. Human Brain Transcriptome. http://hbatlas.org/.

38. ATP Informatics Portal. https://atpportal.org.

39. Gibbs JR, van der Brug MP, Hernandez DG, Traynor BJ, Nalls MA, Lai SL, Arepalli S, Dillman A, Rafferty IP, Troncoso J, Johnson R, Zielke HR, Ferrucci $L$, Longo DL, Cookson MR, Singleton AB: Abundant quantitative trait loci exist for DNA methylation and gene expression in human brain. PLoS Genet 2010, 6:e1000952

40. Ladd-Acosta C, Pevsner J, Sabunciyan S, Yolken RH, Webster MJ, Dinkins T, Callinan PA, Fan JB, Potash JB, Feinberg AP: DNA methylation signatures within the human brain. Am J Hum Genet 2007, 81:1304-1315.

41. Tao S, Yang X, Chen Y, Wang X, Xiao Z, Wang H, Wu Q, Wang X: Up-regulated methyl CpG binding protein-2 in intractable temporal lobe epilepsy patients and a rat model. Neurochem Res 2012, 37:1886-1897.

42. Laird PW: The power and the promise of DNA methylation markers. Nat Rev Cancer 2003, 3:253-266.

43. Sharma S, Kelly TK, Jones PA: Epigenetics in cancer. Carcinogenesis 2010, 31:27-36.

44. Bosch LJ, Mongera S, Terhaar Sive Droste JS, Oort FA, van Turenhout ST, Penning MT, Louwagie J, Mulder CJ, van Engeland M, Carvalho B, Meije $G A$ : Analytical sensitivity and stability of DNA methylation testing in stool samples for colorectal cancer detection. Cell Oncol (Dordr) 2012, 35:309-315

45. Davies MN, Volta M, Pidsley R, Lunnon K, Dixit A, Lovestone S, Coarfa C, Harris RA, Milosavljevic A, Troakes C, Al-Sarraj S, Dobson R, Schalkwyk LC, Mill J: Functional annotation of the human brain methylome identifies tissue-specific epigenetic variation across brain and blood. Genome Biol 2012, 13:R43

46. Kaminsky ZA, Tang T, Wang SC, Ptak C, Oh GH, Wong AH, Feldcamp LA, Virtanen C, Halfvarson J, Tysk C, McRae AF, Visscher PM, Montgomery GW, Gottesman II, Martin NG, Petronis A: DNA methylation profiles in monozygotic and dizygotic twins. Nat Genet 2009, 41:240-245.

47. Koestler DC, Marsit CJ, Christensen BC, Accomando W, Langevin SM, Houseman EA, Nelson HH, Karagas MR, Wiencke JK, Kelsey KT: Peripheral blood immune cell methylation profiles are associated with nonhematopoietic cancers. Cancer Epidemiol Biomarkers Prev 2012, 21:1293-1302. 
48. Wang L, Aakre JA, Jiang R, Marks RS, Wu Y, Chen J, Thibodeau SN, Pankratz VS, Yang P: Methylation markers for small cell lung cancer in peripheral blood leukocyte DNA. J Thorac Oncol 2010, 5:778-785.

49. Mill J, Tang T, Kaminsky Z, Khare T, Yazdanpanah S, Bouchard L, Jia P, Assadzadeh A, Flanagan J, Schumacher A, Wang SC, Petronis A: Epigenomic profiling reveals DNA-methylation changes associated with major psychosis. Am J Hum Genet 2008, 82:696-711.

50. Zhang D, Cheng L, Badner JA, Chen C, Chen Q, Luo W, Craig WR, Redman M, Gershon ES, Liu C: Genetic control of individual differences in gene-specific methylation in human brain. Am J Hum Genet 2010, 86:411-419.

51. Grafodatskaya D, Choufani S, Ferreira JC, Butcher DT, Lou Y, Zhao C, Scherer SW, Weksberg R: EBV transformation and cell culturing destabilizes DNA methylation in human lymphoblastoid cell lines. Genomics 2010, 95:73-83.

52. Liu J, Zhang Z, Bando M, Itoh T, Deardorff MA, Li JR, Clark D, Kaur M, Tatsuro K, Kline AD, Chang C, Vega H, Jackson LG, Spinner NB, Shirahige K, Krantz ID: Genome-wide DNA methylation analysis in cohesin mutant human cell lines. Nucleic Acids Res 2010, 38:5657-5671.

53. Zhang Z, Liu J, Kaur M, Krantz ID: Characterization of DNA methylation and its association with other biological systems in lymphoblastoid cell lines. Genomics 2012, 99:209-219.

54. Nishimura Y, Martin CL, Vazquez-Lopez A, Spence SJ, Alvarez-Retuerto Al, Sigman M, Steindler C, Pellegrini S, Schanen NC, Warren ST, Geschwind DH: Genome-wide expression profiling of lymphoblastoid cell lines distinguishes different forms of autism and reveals shared pathways. Hum Mol Genet 2007, 16:1682-1698.

55. Voineagu I, Wang $X$, Johnston P, Lowe JK, Tian Y, Horvath S, Mill J, Cantor RM, Blencowe BJ, Geschwind DH: Transcriptomic analysis of autistic brain reveals convergent molecular pathology. Nature 2011, 474:380-384.

56. Ballestar E, Ropero S, Alaminos M, Armstrong J, Setien F, Agrelo R, Fraga MF, Herranz M, Avila S, Pineda M, Monros E, Esteller M: The impact of MECP2 mutations in the expression patterns of Rett syndrome patients. Hum Genet 2005, 116:91-104.

57. Colantuoni C, Jeon OH, Hyder K, Chenchik A, Khimani AH, Narayanan V, Hoffamn EP, Kaufmann WE, Naidu S, Pevsner J: Gene expression profiling in postmortem Rett Syndrome brain: differential gene expression and patient classification. Neurobiol Dis 2001, 8:847-865.

58. Delgado IJ, Kim DS, Thatcher KN, LaSalle JM, Van den Veyver IB: Expression profiling of clonal lymphocyte cell cultures from Rett syndrome patients. BMC Med Genet 2006, 7:61.

59. Deng V, Matagne $V$, Banine F, Frerking M, Ohliger P, Budden S, Pevsner J, Dissen GA, Sherman LS, Ojeda SR: FXYD1 is an MeCP2 target gene overexpressed in the brains of Rett syndrome patients and Mecp2-null mice. Hum Mol Genet 2007, 16:640-650.

60. Gibson JH, Slobedman B, NH K, Williamson SL, Minchenko D, El-Osta A, Stern JL, Christodoulou J: Downstream targets of methyl CpG binding protein 2 and their abnormal expression in the frontal cortex of the human Rett syndrome brain. BMC Neurosci 2010, 11:53.

61. Traynor J, Agarwal P, Lazzeroni L, Francke U: Gene expression patterns vary in clonal cell cultures from Rett syndrome females with eight different MECP2 mutations. BMC Med Genet 2002, 3:12.

62. Ulrey CL, Liu L, Andrews LG, Tollefsbol TO: The impact of metabolism on DNA methylation. Hum Mol Genet 2005, 14(Spec No 1):139-147.

63. Lim U, Song MA: Dietary and lifestyle factors of DNA methylation. Methods Mol Biol 2012, 863:359-376.

64. Kennerley SW, Walton ME, Behrens TE, Buckley MJ, Rushworth MF: Optimal decision making and the anterior cingulate cortex. Nat Neurosci 2006, 9:940-947.

65. Rudebeck PH, Buckley MJ, Walton ME, Rushworth MF: A role for the macaque anterior cingulate gyrus in social valuation. Science 2006, 313:1310-1312.

66. Sallet J, Quilodran R, Rothe M, Vezoli J, Joseph JP, Procyk E: Expectations, gains, and losses in the anterior cingulate cortex. Cogn Affect Behav Neurosci 2007, 7:327-336.

67. Na ES, Monteggia LM: The role of MeCP2 in CNS development and function. Horm Behav 2011, 59:364-368.

68. Rusnakova S, Daniel P, Chladek J, Jurak P, Rektor I: The executive functions in frontal and temporal lobes: a flanker task intracerebral recording study. J Clin Neurophysiol 2011, 28:30-35.

69. Hokfelt T, Pernow B, Wahren J: Substance P: a pioneer amongst neuropeptides. J Intern Med 2001, 249:27-40.
70. Mai JK, Stephens PH, Hopf A, Cuello AC: Substance P in the human brain. Neuroscience 1986, 17:709-739.

71. Chahrour M, Zoghbi HY: The story of Rett syndrome: from clinic to neurobiology. Neuron 2007, 56:422-437.

72. Pena F, Ramirez JM: Substance P-mediated modulation of pacemaker properties in the mammalian respiratory network. J Neurosci 2004, 24:7549-7556.

73. Gene Expression Omnibus. http://www.ncbi.nlm.nih.gov/geo/.

doi:10.1186/1866-1955-5-15

Cite this article as: Aldinger et al: Comparative DNA methylation among females with neurodevelopmental disorders and seizures identifies TAC1 as a MeCP2 target gene. Journal of Neurodevelopmental Disorders 2013 5:15.

\section{Submit your next manuscript to BioMed Central and take full advantage of:}

- Convenient online submission

- Thorough peer review

- No space constraints or color figure charges

- Immediate publication on acceptance

- Inclusion in PubMed, CAS, Scopus and Google Scholar

- Research which is freely available for redistribution

Submit your manuscript at www.biomedcentral.com/submit
C) BioMed Central 